\title{
Vulnerability of oceanic dune systems under wind pattern change scenarios in Uruguay
}

\author{
Daniel Panario*, Gustavo Piñeiro \\ Unidad de Ciencias de la Epigénesis, Facultad de Ciencias, Universidad de la República, Tristán Narvaja 1674, \\ Montevideo, Uruguay
}

\begin{abstract}
The dynamics of the large dune systems adjacent to lowlands and to the oceanic coastline in Uruguay is likely to be affected both by sea level rise and wind circulation patterns. A simple eolian sand transport model, which relates wind friction, frequency and direction to sand transport, was used to estimate annual sand transport as a measure of the impact of potential climate changes on the stability of dune systems and beaches. The model was adjusted to local conditions using real wind-matrix and eolian-transport data from the past 5 decades. The climate change scenarios considered assume a positive or negative $10 \%$ change in the frequency of the South Atlantic Anticyclone winds, since its position determines the near-surface wind circulation pattern. Results obtained at the Cabo Polonio study area indicate that, in the medium and long term, coastal recession is likely to occur due to a decrease in coastal dunefield activity induced by changes in wind pattern. It was also observed that, should current anthropogenic impact in the area remain unchanged, the situation would be equally serious even under a non-climate-change scenario. This is due to the fact that the forestation process that has taken place over the past 20 yr has caused the immobilization of a significant portion of the dune system, preventing natural sand transfer to the coast. In recent years a still insufficient deforestation effort, intended to stop coastline recession, has taken place.
\end{abstract}

KEY WORDS: Climate change $\cdot$ Coastal dynamics $\cdot$ Coastal dunes $\cdot$ Forestation

\section{INTRODUCTION}

Coastal areas of the world are being increasingly impacted by human activities, both at the global level (climate changes and sea level rise) and at the local level (e.g. land occupation, water pollution). Interest in assessing the potential effects of coastal use and occupation, as well as the possibility of implementing impact-mitigation measures, has consequently increased (National Research Council 1994).

Historical wind circulation patterns and the changes caused by their oscillations in Uruguay have long been documented, both in the national (Antón \& Goso 1974) and regional (Iriondo \& García 1993) literature. Cyclic

\footnotetext{
•E-mail: panari@fcien.edu.uy
}

predominance of Atlantic and Pacific atmospheric circulation patterns has been mentioned in both cases to explain sediment records and wind patterns during different episodes of the Quaternary and the Holocene. This observation is based particularly on the resemblance of past annual winter and summer patterns to current ones, on the palaeo-beach arc morphology, and on physico-chemical characteristics of the deposits and their alteration products (Panario \& Piñeiro 1992).

In this study a simple model adjusted to local conditions was used to analyse the effects of small variations in wind pattern on dunes and sandy beaches. The hypothesis was based on existing evidence regarding the sensitivity of coastal dunes, extensively developed in temperate humid regions, to global climate changes (Brookfield 1970, Hesp \& Thom 1990, Pye 1993). To a 
large extent, sediment exchange between the beach and dune environments is controlled by the 'effective' wind pattern (determined by the frequency of the strongest winds) (Hsu 1973, Svaseck \& Terwindt 1974, Hunter et al. 1983, Nordstrom \& Jackson 1992).

The presence of dune systems is determined by the wind pattern, coastal configuration, land management, sand availability and vegetation. Therefore, eolian transport models need to be adjusted to local conditions in order to simulate future scenarios (Castel 1988, Sarre 1989, Chapman 1990, Dingler et al. 1992, Pluis 1992).

The study area was Cabo Polonio, located on the Uruguay oceanic coast at $53^{\circ} 45^{\prime} \mathrm{W}$ latitude, $34^{\circ} 23^{\prime} \mathrm{S}$ longitude. This is the last active relict of a transgressive coastal dune system. It covers $35 \mathrm{~km}^{2}$, and is almost parallel with the coastline (Figs. 1 \& 2).

The study was carried out in 3 steps:

(1) Measurement of current sand transport ranges using standard traps and aerial photographs from a $47-y r$ series.

(2) Measurement of current eolian transport on the basis of actual meteorological records, by means of a model adjusted according to the results of step (1).

(3) Development of 2 scenarios with $10 \%$ change in the frequency of NE and SW winds respectively.

\section{METHODOLOGY}

\subsection{General approach}

Sand traps of the Leattermand (1978) type were first used to assess the behaviour of the Bagnold (1941) equation [on which the Fryberger (1979) eolian sand transport model is based] in the study area. This was performed at different time scales (minutes to days).

Secondly, dune displacements were assessed by analyzing aerial photographs from a time series covering $47 \mathrm{yr}$ (aerial photographs from 1943, 1966, 1967. $1986,1989,1990$ ), as well as wind records.

Thirdly, the Fryberger (1979) model was used to develop 2 climate change scenarios with a $10 \%$ increase and decrease, respectively, in first and third quadrant wind frequencies.

\subsection{Model description}

The model is based on the assumption that the relationship between wind friction and velocity is linear. This is a normally accepted assumption which has the advant-age of allowing for the estimate of the potential transport in areas where standard weather station records are available. In addition, local correction variables, such as substrate characteristics, are included in the wind velocity threshold value $\left(V_{t}\right)$.

The potential transport is numerically expressed in vectorial units (VU), which are proportional to the product of a weighting factor $\left[V^{2}\left(V-V_{t}\right)\right] / 100$ times the percentage of total wind records at a given time $(t)$, as follows:

$$
V U=\left[V^{2}\left(V-V_{t}\right)\right] / 100 \times t
$$

Wind velocity is measured in knots and VU is converted to $\mathrm{m}^{3} \mathrm{~m}^{-1} \mathrm{yr}^{-1}$ by means of the relation proposed by Fryberger et al. (1984): $14 \mathrm{VU}$ are equal to $1 \mathrm{~m}^{3} \mathrm{~m}^{-1}$ $\mathrm{yr}^{-1}$. The sum of vectors of the data matrix is the sand rose, which is represented by a vector of length equal to the VU magnitude and direction equal to the direction of the transport (as opposed to wind origin). 


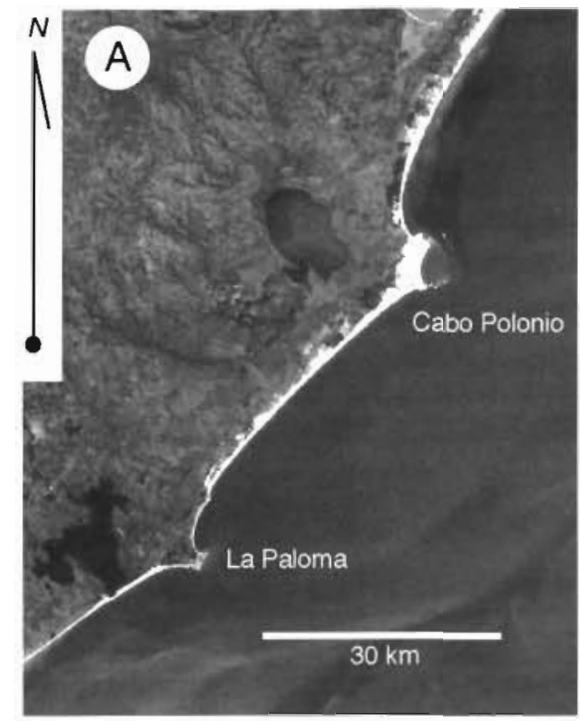

Fig 2. (A) Regional dune systems, Uruguay, 1987 Landsat image. (B) Dunes at the study area; 1986 aerial photograph

\section{RESULTS}

\subsection{Sand transport model calibration}

A preliminary adjustment was carried out by monitoring 23 active transport trap samples under the prevailing winds (SW and NE). Measurements were taken on December 16,17, 18 and 19, 1992. Measurements for a second adjustment were taken at shorter intervals, including different sand bedforms: barchan (crescentic dune with slip face), beach, and dome (dune without slip faces). Some of the most relevant results of the calibration process are shown in Table 1.

\subsection{Dune advance}

The mean dune displacement value for the 1943 to 1966 period was $105 \mathrm{~m}$ (4.56 $\mathrm{m} \mathrm{yr}^{-1}$ ) in the southern sector, with an ENE direction. This value progressively decreases to $65 \mathrm{~m}$ in the northern sector $\left(2.82 \mathrm{~m} \mathrm{yr}^{-1}\right)$ with a

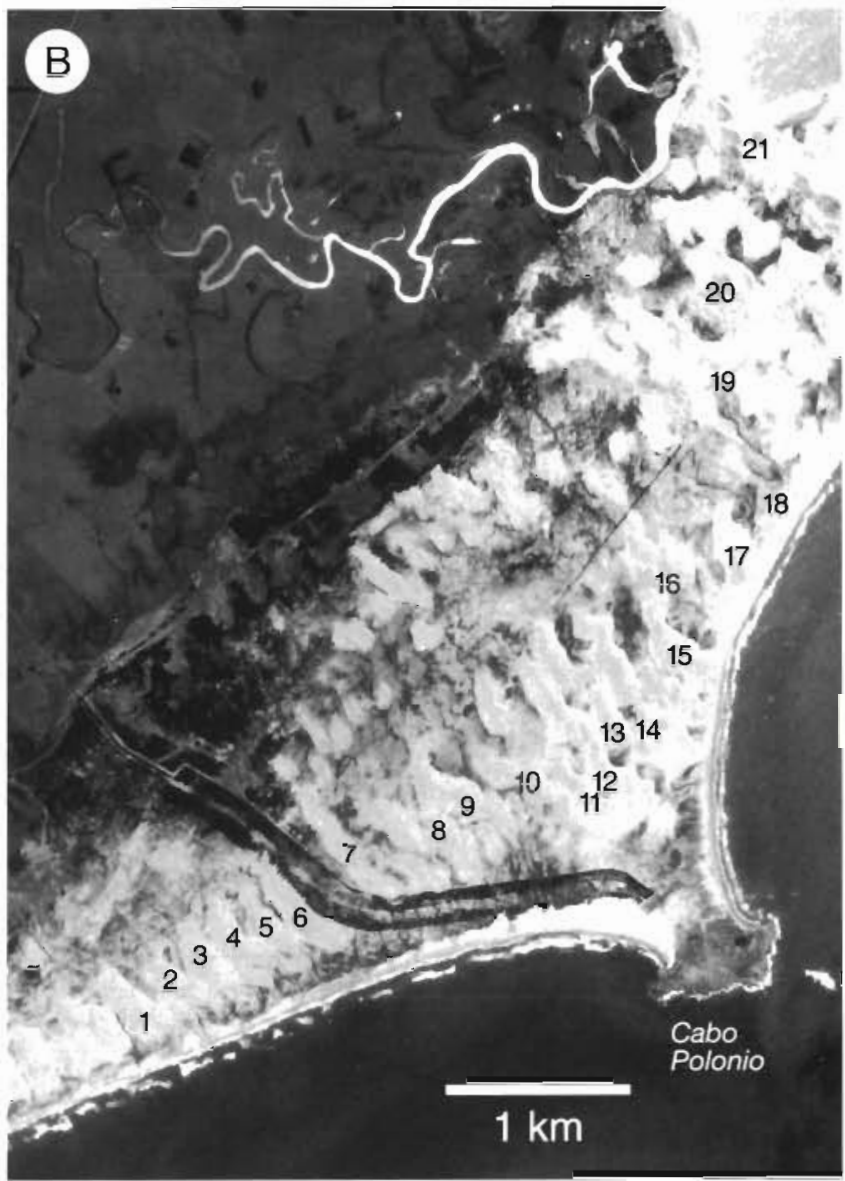

direction ranging from NNE to ENE. The standard deviation (of a total of 26 values) was higher in the northern sector $(14.7 \mathrm{~m})$ than in the southern sector $(12.8 \mathrm{~m})$, even though the mean value of the former was lower.

Displacements of up to $10 \mathrm{~m} \mathrm{yr}^{-1}$ were measured in the overlapping sector during the period from May 13, 1966, to March 8, 1967, with a mean value of $6.7 \mathrm{~m} \mathrm{yr}^{-1}$.

Displacements from 1967 to 1986 reached a maximum value of $132 \mathrm{~m}\left(6.9 \mathrm{~m} \mathrm{yr}^{-1}\right)$, with a mean of $90 \mathrm{~m}$ $\left(4.73 \mathrm{~m} \mathrm{yr}^{-1}\right)$.

Table 1. Daily measured eolian sand transport at Cabo Polonio

\begin{tabular}{|lccc|}
\hline Site & Barchan & Beach & Dome \\
\hline Record duration (s) & 940 & 970 & 940 \\
Mean wind velocity at $2{\mathrm{~m}\left(\mathrm{~m} \mathrm{~s}^{-1}\right)}^{-1}$ & 9.70 & 9.10 & 11.22 \\
Minimum wind velocity $\left(\mathrm{m} \mathrm{s}^{-1}\right)$ & 8.10 & 6.90 & 8.00 \\
Standard deviation $\left(\mathrm{m} \mathrm{s}^{-1}\right)$ & 1.20 & 1.28 & 1.15 \\
Direction & $\mathrm{SW}$ & $\mathrm{SW}$ & $\mathrm{SW}$ \\
Observed transport $\left(\mathrm{g} \mathrm{cm}^{-1} \mathrm{~s}^{-1}\right)$ & 0.4720 & 0.3202 & 0.4707 \\
Calculated transport $\left(\mathrm{g} \mathrm{cm}^{-1} \mathrm{~s}^{-1}\right)$ & 0.4719 & 0.3264 & 0.4721 \\
\hline
\end{tabular}


The most recent measurements (100 records) correspond to the 1989 to 1990 period, with a mean value of $4.3 \mathrm{~m}$ in the central sector for a 9 mo period.

The measured values, together with the 1943-1992 model estimates, are shown in Fig. 3.

\subsection{Potential transport rates}

The potential transport value estimated using the Fryberger (1979) standard parameters for the 1974 wind table is $2833 \mathrm{VU}$, which corresponds to $198 \mathrm{~m}^{3}$ $\mathrm{m}^{-1} \mathrm{yr}^{-1}$. The transport resulting from the vectorial sum is $48.1 \mathrm{~m}^{3} \mathrm{~m}^{-1} \mathrm{yr}^{-1}$, with a $\mathrm{N} 29.2^{\circ}$ E direction, and a sand exchange with the beach on the order of $3.7 \times 10^{4}$ t $\mathrm{yr}^{-1}$.

Field studies have shown that results may vary in Cabo Polonio given different $V_{\mathrm{t}}$ values. Thus, potential transport is reduced to $13 \mathrm{~m}^{3} \mathrm{~m}^{-1} \mathrm{yr}^{-1}$ towards the ENE direction if a threshold wind velocity value of $15 \mathrm{~m} \mathrm{~s}^{-1}$ is selected (corresponding to the coarser sand dunes of the southern sector). In contrast, if the threshold values are reduced (in accordance with the observed S-N grain size reduction), the transport magnitude values get progressively closer to the standard $V_{\mathrm{t}}=12$ knots assumed by Fryberger (1979) and turn counterclockwise.

\subsection{Eolian sand transport rates under a Pacific Anticyclone predominance scenario}

Under a scenario with a $10 \%$ increase in the frequency of SSW, SW and WSW winds and a 10\% decrease in the NNE, NE and ENE winds (assuming

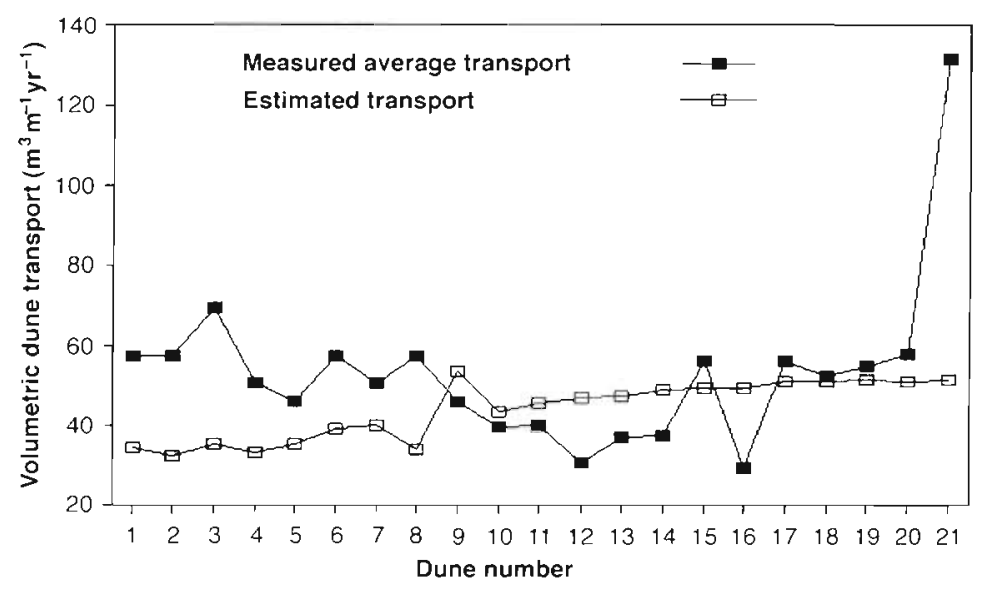

Fig. 3. Measured and estimated volumetric dune displacements for the perrod 1943 to 1992 that the other parameters remain unchanged) the value of the potential eolian sand transport (after solving the vectorial sum) is $60.8 \mathrm{~m}^{3} \mathrm{~m}^{-1} \mathrm{yr}^{-1}$ with a $\mathrm{N} 32^{\circ} \mathrm{E}$ direction.

\subsection{Eolian sand transport rates under an Atlantic Anticyclone predominance scenario}

Under a scenario with $10 \%$ increase in the frequency of NNE, NE and ENE winds and 10\% decrease in the SSW, SW and WSW winds (assuming that the other parameters remain unchanged) the value of the potential eolian sand transport (after solving the vectorial sum) is $36.2 \mathrm{~m}^{3} \mathrm{~m}^{-1} \mathrm{yr}^{-1}$ with a $\mathrm{N} 23^{\circ}$ E direction.

\section{DISCUSSION}

If mean transport during the study is equivalent to the volume displaced by the dunes, as assumed by Lettau \& Lettau (1969) and Hunter et al. (1983), then the estimated volumes are consistent with the real values. Since dunes are about $10 \mathrm{~m}$ high, an annual advance of $5 \mathrm{~m}$ is equivalent to a displacement of $50 \mathrm{~m}^{3} \mathrm{~m}^{-1} \mathrm{yr}^{-1}$. This value is of the same order of magnitude as the estimates for both Cabo Polonio and La Paloma-a densely urbanized zone located a few $\mathrm{km}$ SW of Cabo Polonio. The estimated direction of the dune displacement is also consistent with the observations.

Extrapolating these results to the hypothetical scenarios suggests that even small variations in the wind circulation pattern $(10 \%)$ would cause a $50 \%$ reduction of sand transfer to beaches of the northern and eastern sectors, particularly under the prevailing Atlantic Anticyclone condition (Fig. 4).

The scenario above is the most likely to occur according both to projections of the general circulation models GFDL (Geophysical Fluid Dynamics Laboratory), UKMO (United Kingdom Meteorological Office), and GISS (Goddard Institute for Space Science) (R. Hofstadter \& M. Bidegain pers. comm.) and to morphologic and sedimentary evidence of regional landscape evolution.

Sand transfer to the coast following the forestation process initiated in 1970 suggests that the volume retained is proportional to the area involved $(70 \%)$. The deforestation measures that have been recently adopted are clearly insufficient to recover the normal system behaviour.

The results above also indicate that the whole dune system under study is moving northwards. This transgression does not take 


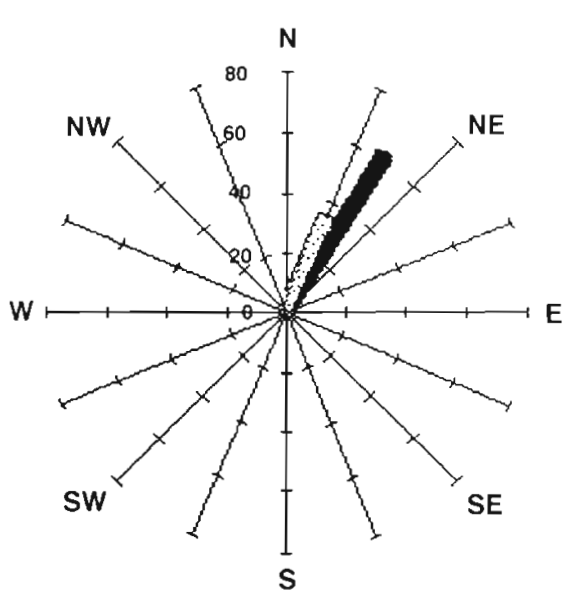

Scenario with $10 \%$ increase in frequency of SW winds Scenario with $10 \%$ increase in frequency of NE winds

Fig. 4. Expected changes in direction and magnitude of eolian sand transport under wind pattern change scenarios. Sand transport vectors given in $\mathrm{m}^{3} \mathrm{~m}^{-1} \mathrm{yr}^{-1}$

place in a single direction, but as a sequential transport which can be, in theory, vectorially added up. Part of the material is, however, exported out of the system boundaries, since one of the northern components has progressively covered the adjacent wetlands.

In spite of the likelihood of sand being transported out of the beach area and towards the dunes, it has been demonstrated that the measured transport ranges are not only dependent on sand supply from the berm, the beach face or other parts of the beach (Panario \& Pineiro 1992). In fact, they are partly originate locally as a result of erosion of old sandy soils, which are currently appearing in the southern fields. This fact is evidence of undersaturation of the flux in this sector, which is caused by the above-mentioned forestation process.

Given the uncovering of soils as a result of erosion, the coastline becomes exposed to the direct action of the waves. This effect becomes visible $3000 \mathrm{~m}$ west of Cabo Polonio. The contrary occurs on the opposite side, where the old soils are being covered and are only visible on the watershed of small streams running between dunes close to the coastline.

\section{CONCLUSIONS}

Results from field measurements of eolian sand transport at the Cabo Polonio dune system, carried out at various time scales and with different spatial orientations, indicate a considerable seaward transfer of continental sand on the order of $37000 \mathrm{t} \mathrm{yr}^{-1}$ to the beaches facing east and northeast.
Simulations performed with an empirical-mathematical model, calibrated under a wide range of local conditions, indicate that a $10 \%$ increase in the frequency of winds associated with the South Atlantic Anticyclone would reduce by one half the sand availability at the beaches oriented to the east and northeast. This fact, added to the projected increase in sea level and the dune immobilization process, calls for the immediate adoption of management measures in order to allow for the recovery of the system dynamics. It is also necessary to implement a monitoring program on marine processes in this area, given its high vulnerability to erosion.

Acknowledgements. The authors thank their colleagues from the Unidad de Ciencias de Epigénesis and the Departamento de Meteorología of the Facultad de Ciencias for their support in the conduct of this study. The support provided by the Intendencia Municipal de Rocha authorities during 1992 and 1993 is also acknowledged.

\section{LITERATURE CITED}

Antón D, Goso H (1974) Estado actual de los conocimientos sobre el Cuaternario en el Uruguay. In: Anais do XXVIIl Congresso Brasileiro de Geologia, Porto Alegre 3: 151-157

Bagnold RA (1941) The physics of blown sand and desert dunes. Methuen, London

Brookfield M (1970) Dune trends and wind regime in Central Australia. Z Geomorphol Suppl 10:121-153

Castel IIY (1988) A simulation model of wind erosion and sedimentation as a basis for management of a drift sand area in the Netherlands. Earth Surface Processes Landforms 13:501-509

Chapman D (1990) Aeolian sand transport-an optimized model. Earth Surface Processes Landforms 15:751-760

Dingler JR, Hsu SA, Reiss TE (1992) Theoretical and measured aeolian sand transport on a barrier island, Louisiana, USA. Sedimentology 39:1031-1043

Fryberger SG (1979) Dune forms and wind regime. In: McKee ED (ed) A study of global sand seas. Prof Pap US Geol Surv 1052:137-169

Fryberger SG, Al-Sari AM, Clisham TJ, Rizvi SAR, Al-Hinai KG (1984) Wind sedimentation in the Jafurah sand sea, Saudi Arabia. Sedimentology 31:413-431

Hesp PA, Thom BG (1990) Geomorphology and evolution of active transgressive dunefields. In: Nordstrom KF, Psuty NP, Carter RWG (eds) Coastal dunes: form and process. Wiley, Chichester, p 253-288

Hsu SA (1973) Computing eolian sand transport from shear velocity measurements. J Geol 81:739-743

Hunter RE, Richmond BM, Alpha TR (1983) Storm-controlled oblique dunes of the Oregon coast. Bull Geol Soc Am 94: $1450-1565$

Iriondo $\mathrm{MH}$, García NO (1993) Climatic variations in the Argentine plains during the last 18000 years. Palaeogeogr Palaeoclimatol Palaeoecol 101:209-220

Leattermand SP (1978) A new eolian sand trap design. Sedimentology 25:303-306

Lettau K, Lettau $H$ (1969) Bulk transport of sand by the barchans of the Pampa de la Joya in southern Peru. Z Geomorphol 13:182-195 
National Research Council (1994) The ocean's role in global change. National Academic Press, Washington, DC

Nordstrom KF, Jackson NL (1992) Effect of source width and tidal elevation changes on aeolian transport on an estuarine beach. Sedimentology 39:769-778

Panario D, Piñeiro G (1992) Dinámica sedimentaria y geomorfológica de dunas y playas en Cabo Polonio. Unidad de Ciencias de la Epigénesis, Facultad de Ciencias, Universidad de la República, Montevideo

Pluis JLA (1992) Relationships between deflation and near surface wind velocity in a coastal dune blowout. Earth
Surface Processes Landforms 17:663-673

Pye K (1993) The nature and significance of aeolian sedimentary systems. In: Pye K (ed) The dynamics and environmental context of aeolian sedimentary systems. Geological Society Special Publication No. 72, London

Sarre RD (1989) Aeolian sand drift from the intertidal zone on a temperate beach: potential and actual rates. Earth Surface Processes Landforms 14:247-258

Svaseck JN, Terwindt JHJ (1974) Measurements of sand transport by wind on a natural beach. Sedimentology 21 : $311-322$ 